\title{
Pengaruh Kualitas Pelayanan Dan Harga Yang Dimediasi Oleh Kepuasan Pelanggan Terhadap Loyalitas Pelanggan
}

\author{
Deddy Rakhmad Hidayat ${ }^{1)}$ \\ Fakultas Ekonomi dan Bisnis \\ Universitas Palangka Raya, Indonesia \\ Peridawaty $^{2)}$ \\ Fakultas Ekonomi dan Bisnis \\ Universitas Palangka Raya, Indonesia
}

Email: drhidayatse@gmail.com

\begin{abstract}
Abstrak
Tujuan - Penelitian ini bertujuan untuk menguji dan menganalisis pengaruh kualitas layanan dan harga terhadap loyalitas pelanggan yang dimediasi oleh kepuasan pelanggan.

Desain/Methodologi/Pendekatan - Metode penelitian dilakukan dengan menggunakan pendekatan kuantitatif, pengumpulan data menggunakan kuesioner sebagai instrumen pengumpulan data utama untuk seluruh objek penelitian. Responden yang menggunakan total 110 pelanggan Speedy di Palangka Raya. Teknik analisis data menggunakan Partial Least Square (PLS) dengan perangkat lunak SMARTPLS 3.0. Temuan penelitian - Hasil pengujian hipotesis menunjukkan bahwa kualitas layanan berpengaruh positif dan signifikan terhadap kepuasan pelanggan, harga tidak berpengaruh signifikan terhadap kepuasan pelanggan, kepuasan pelanggan berpengaruh positif dan signifikan terhadap loyalitas pelanggan, kualitas layanan memiliki pengaruh positif dan signifikan. dan pengaruh signifikan terhadap loyalitas pelanggan dimediasi oleh kepuasan pelanggan, dan harga memiliki efek positif dan signifikan untuk loyalitas pelanggan dimediasi oleh kepuasan pelanggan.
\end{abstract}

Kata kunci: Kualitas Layanan, Harga, Kepuasan Pelanggan dan Loyalitas Pelanggan

\section{Effect Of Service Quality And Price Mediated By Customer Satisfaction On Customer Loyalty}

\section{Abstract}

Purpose - This study aims to examine and analyze the effect of service quality and price on customer loyalty mediated by customer satisfaction.

Design / Methodology / Approach - The research method is carried out using a quantitative approach, data collection uses a questionnaire as the main data collection instrument for all research objects. Respondents who use a total of 110 Speedy subscribers in Palangka Raya. The data analysis technique used Partial Least Square (PLS) with SMARTPLS 3.0 software.

Findings - The results of hypothesis testing indicate that service quality has a positive and significant effect on customer satisfaction, price has no significant effect on customer satisfaction, customer satisfaction has a positive and significant effect on customer loyalty, service quality has a positive and significant effect. and a significant effect on customer loyalty is mediated by customer satisfaction, and price has a positive and significant effect on customer loyalty mediated by customer satisfaction.

Jurnal Manajemen Sains dan Organisasi Vol 1, No 1, 2020 pp. 16-27 FEB UPR Publishing $2685-4724$
Deddy Rakhmad Hidayat, Perdiawaty. Published in Jurnal Manajemen Sains dan Organisasi. Published by Departement of Management FEB Limited. This article is published under the Creative Commons Attribution (CC BY 4.0) licence. Anyone may reproduce, distribute, translate and create derivative works of this article (for both commercial and non-commercial purposes), subject to full attribution to the original publication and authors. 


\section{Pendahuluan}

Berdasarkan penelitian terdahulu tentang loyalitas konsumen, didapati bahwa loyalitas dipengaruhi oleh variabel kepuasan pelanggan (customer satisfaction), harga (price), dan kualitas pelayanan (service quality) (Bei dan Chiao, 2001; Akbar dan Parvez, 2009; Krismanto, 2009; Syafiq, 2010; Chang dan Fong, 2010; Ishaq 2012). Akan tetapi temuan penelitian terdahulu juga menyatakan hal yang bertentangan (research gap) dengan temuan di atas, yaitu bahwa loyalitas tidak dipengaruhi oleh variabel kepuasan pelanggan, harga, dan kualitas pelayanan. (Akbar dan Munir 2009; Cheng dkk, 2009; Aidasanti, 2010; Syafiq, 2010; Boohene dan Agyapong 2011; Cheng et al 2011; Eid 2011; dan Ishaq 2012). Singh (2006) juga menyatakan kepuasan merupakan faktor langsung dari loyalitas pelanggan. Variabel kepuasan pelanggan (customer satisfaction) mempunyai korelasi positif dan sangat signifikan dengan loyalitas pelanggan (customer loyalty) (Akbar dan Parvez, 2009; Anuwichanont dan Mechinda, 2009; Krismanto, 2009; Syafiq, 2010; Chen dkk, 2010; Eid 2011). Namun di sisi lain, masih ada pertentangan mengenai hal ini (research gap) misalnya Andreassen dan Lindestad (1997) menyatakan bahwa kepuasan pelanggan tidak berpengaruh signifikan terhadap loyalitas. Boohene dan Agyapong (2011) menemukan bahwa Customer satisfaction mempunyai hubungan negatif dengan customer loyalty. Loyalitas pelanggan dan kepuasan pelanggan dipengaruhi oleh kualitas pelayanan (service quality), seperti yang dinyatakan oleh Bei dan Chiao (2001) bahwa kualitas pelayanan yang dirasakan pelanggan sangat berpengaruh terhadap loyalitas pelanggan melalui kepuasan pelanggan. Service quality yang mengadopsi riset dari Parasuraman, Zeithaml dan Berry (1988) mengidentifikasikan faktor penentu kualitas pelayanan yaitu tangibles, reliability, responsiveness, empathy dan assurance. Akbar dan Parvez (2009) mengungkapkan bahwa reliability, responsiveness, assurance, empathy dan tangibles mempunyai korelasi positif dan sangat signifikan dengan kepuasan pelanggan dan loyalitas pelanggan. Omar et al. (2009) mengungkapkan bahwa kualitas pelayanan mempengaruhi kepuasan pelanggan secara signifikan. Krismanto (2009) pun menemukan hal yang sama bahwa kualitas pelayanan berdampak positip terhadap kepuasan pelanggan. Akan tetapi, terdapat pula riset yang menyatakan tidak ada pengaruh kualitas pelayanan terhadap loyalitas pelanggan, seperti riset Hellier et al., (2003) mengemukakan bahwa kualitas pelayanan tidak secara langsung mempengaruhi kepuasan pelanggan atau memiliki sedikit pengaruh terhadap kepuasan pelanggan. Parvez (2005) yang menyatakan bahwa service quality (reliability, responsiveness, assurance, empathy, tangibility) tidak memiliki hubungan signifikan dengan customer Loyalty. Cheng dkk (2009) dan Syafiq (2010) juga menyatakan bahwa kualitas pelayanan tidak berpengaruh signifikan secara langsung terhadap loyalitas pelanggan. Bei dan Chiao (2001) menyatakan bahwa harga yang dirasakan wajar berpengaruh secara langsung terhadap loyalitas pelanggan atau tidak langsung melalui kepuasan pelanggan. Djati dan Darmawan (2004) menyatakan bahwa variabel harga memiliki pengaruh terhadap kepuasan pelanggan. Cheng dkk (2009) menyatakan harga (price) mempengaruhi loyalitas. Sedangkan Angin (2009) menyatakan bahwa harga tidak berpengaruh terhadap kepuasan pelanggan. Aidasanti (2010) dan Cheng et al (2011) menyatakan bahwa price fairness tidak berpengaruh secara langsung terhadap customer loyalty ataupun dimediasi oleh customer satisfaction.

PT Telkom Tbk merupakan perusahaan BUMN di bidang Telekomunikasi adalah 
leader market di Indonesia untuk bisnis broadband dengan memberikan pelayanan Telecommunication, Information, Media, Edutainment dan Services (TIMES). Upaya ini membuahkan hasil yang baik, dengan peningkatan jumlah pelanggan Telkomspeedy, dimana sampai tanggal 31 Desember 2015, PT Telkom Tbk melayani 3.983.000 pelanggan Speedy dengan pertumbuhan sebesar 17,2\% dibandingkan sampai tanggal 31 Desember 2014 sebesar 3.400.000 pelanggan. (Laporan Tahunan PT Telkom Tbk 2015). Meskipun mengalami peningkatan baik pendapatan dan jumlah pelanggan, permasalahan yang hampir ada di seluruh wilayah Indonesia yaitu terdapat pengaduan dari pelanggan Speedy. Jenis pengaduan yang sering dikeluhkan pelanggan yaitu gangguan jaringan, kecepatan akses yang tidak stabil, koneksi yang sering putus, serta penanganan gangguan yang lambat. Ketidakpuasan pelanggan akan berdampak pada cabutan (churn) atau berhenti berlangganan yang terus meningkat. (Hidayat, D.R. dan Firdaus, M.R., 2014).

\section{Tinjauan Pustaka}

Wijayanti (2008) menyatakan bahwa Lewis dan Booms (1983) merupakan pakar yang pertama kali mendefinisikan kualitas jasa sebagai ukuran seberapa bagus tingkat pelayanan yang diberikan mampu sesuai dengan ekspektasi pelanggan. Parasuraman dkk (1988) mengidentifikasikan faktor-faktor penentu kualitas pelayanan yaitu tangibles, reliability, responsiveness, assurance dan empathy. Tangibles yaitu peralatan modern, fasilitas visual yang menarik, petugas yang berpenampilan rapi, fasilitas pendukung yang berhubungan dengan pelayanan. Reliability yaitu memberikan pelayanan sesuai janji, mempunyai kemampuan untuk mengatasi masalah pelayanan pelanggan, memberikan pelayanan yang benar sejak awal, memberikan pelayanan pada waktu yang telah dijanjikan, menjaga informasi akurat. Responsiveness yaitu selalu memberitahu pelanggan kapan pelayanan akan diberikan, mengutamakan pelayanan ke pelanggan, mempunyai kemauan untuk menolong pelanggan, selalu siap untuk merespon permintaan pelanggan. Assurance yaitu petugas yang dapat menumbuhkan rasa percaya diri pelanggan, membuat pelanggan merasa aman dalam bertransaksi, petugas yang selalu ramah, petugas yang mempunyai pengetahuan untuk menjawab pertanyaan pelanggan. Emphaty yaitu memberikan perhatian secara individual, mendapatkan hati pelanggan, petugas yang mengerti kebutuhan pelanggan, dan jam kerja yang tepat dalam melayani pelanggan.

Harga merupakan biaya moneter untuk pelanggan untuk membeli produk atau jasa. Harga adalah determinan penting yang mempengaruhi keputusan membeli pelanggan. (Zhang dan Feng 2009). Harga merupakan salah suatu faktor penentu dalam pemilihan merek yang berkaitan dengan keputusan membeli konsumen. Harga merupakan satu-satunya elemen pada marketing mix yang menghasilkan pendapatan, elemen yang lain justru mengeluarkan biaya. (Wijayanti, 2008). Bei dan Chiao (2001) menyatakan bahwa kewajaran harga yang dirasakan berhubungan dengan kepuasan pelanggan. Semakin tinggi tingkat kewajaran harga yang dirasakan pelanggan, kepuasan akan meningkat. Wijayanti (2008) menyatakan bahwa terdapat hubungan positif antara harga dan kepuasan. Pelanggan yang membayar dengan pengorbanan lebih dan mendapatkan manfaat yang baik, akan merasa puas. Indikator Harga terdiri dari perkiraan harga, kesesuaian pengorbanan, dan kewajaran harga. Perkiraan Harga yaitu untuk mengetahui harga tersebut tidak berbeda jauh dengan perkiraan pelanggan. 
Kesesuaian Pengorbanan yaitu untuk mengetahui seberapa sesuai harga yang diberikan perusahaan dengan produk dan jasa yang ditawarkan. Kewajaran Harga yaitu untuk mengetahui kewajaran harga yang ditawarkan perusahaan jika dibandingkan dengan pesaing. (Djati dan Darmawan 2004; Bei dan Chiao 2007; dan Wijayanti 2008)

Kepuasan adalah tingkat keadaan perasaan seseorang setelah membandingkan kinerja suatu produk yang ia rasakan dibanding harapannya (Kotler dan Keller, 2011). Kepuasan yang dirasakan pelanggan dapat meningkatkan intensitas membeli dari pelanggan tersebut (Wijayanti 2008). Dengan terciptanya tingkat kepuasan pelanggan yang optimal, mendorong terciptanya loyalitas di benak pelanggan yang merasa puas tadi. Kepuasan sebagai tanggapan pelanggan yaitu penilaian atas fitur produk dan jasa, bahkan produk dan jasa itu sendiri, yang memberikan tingkat kesenangan dalam mengkonsumsi yang berhubungan dengan pemenuhan kebutuhan, (Angin 2009). Indikator kepuasan pelanggan meliputi: Experience yaitu menunjukkan kepuasan pelanggan selama menjalin hubungan dengan perusahaan. Expectation yaitu menunjukkan kesesuaian produk atau jasa yang ditawarkan dengan pengharapan pelanggan sebagaimana dipersepsikan oleh pelanggan. Overall Satisfaction yaitu menunjukkan tingkat kepuasan pelanggan terhadap penyedia jasa pelayanan secara keseluruhan. (Wijayanti, 2008)

Loyalitas pelanggan merupakan suatu bentuk perilaku konsumen yang mengarah pada kemungkinan pembelian ulang, meningkatnya loyalitas pada harga, dan memberikan rekomendasi pada pihak lain (Agung 2006). Kini konsep kesetiaan pelanggan yang dalam perkembangan awalnya lebih menitikberatkan pada aspek perilaku, dikembangkan lebih luas lagi dengan melibatkan dimensi sikap dan perilaku. Wijayanti (2008) menyatakan bahwa kesetiaan dipandang sebagai hubungan erat antara sikap dengan perilaku pembelian ulang. Indikator loyalitas pelanggan meliputi: Melanjutkan Penggunaan yaitu untuk mengetahui seberapa loyal sikap konsumen untuk tetap menggunakan produk di masa datang. Rekomendasi Pada Orang Lain yaitu untuk mengetahui seberapa loyal konsumen dalam merekomendasikan produk kepada orang lain. Ketahanan untuk tidak pindah ke produk lain yaitu untuk mengetahui seberapa loyal sikap konsumen dalam bertahan menggunakan produk, walaupun ada produk pesaing yang lebih murah.

Hipotesis dalam riset ini yaitu:

H1: Kualitas pelayanan berpengaruh positif dan signifikan terhadap kepuasan pelanggan.

$\mathrm{H} 2$ : Harga berpengaruh positif dan signifikan terhadap kepuasan pelanggan.

H3: Kepuasan pelanggan berpengaruh positif dan signifikan terhadap loyalitas pelanggan.

H4: Kualitas pelayanan berpengaruh positif dan signifikan terhadap loyalitas pelanggan yang dimediasi oleh kepuasan pelanggan.

H5: Harga berpengaruh positif dan signifikan terhadap loyalitas pelanggan yang dimediasi oleh kepuasan pelanggan. 


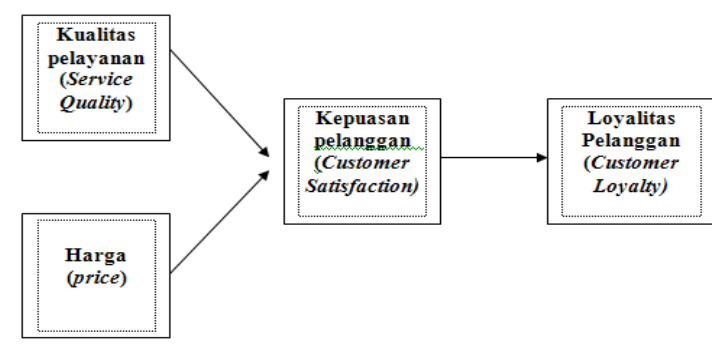

Gambar 1 Model Penelitian

Sumber: Wijayanti (2008); Akbar dan Parvez (2009), dikembangkan untuk penelitian ini (2019)

\section{Metode Penelitian}

Penelitian ini merupakan penelitian dasar yang bertujuan mengembangkan ilmu untuk mencari jawaban baru atas masalah loyalitas pelanggan yang terjadi di perusahaan Telkom Speedy dengan pendekatan kuantitatif. Tempat penelitian dilaksanakan di Kota Palangka Raya, Kalimantan Tengah. Unit analisis dalam penelitian ini adalah individu, yaitu pelanggan PT Telkom yang menggunakan Speedy di Palangka Raya. Populasi dalam penelitian ini adalah seluruh pelanggan Speedy di Palangka Raya. Ghozali (2011) merekomendasikan ukuran sampel antara 100 sampai 200 untuk analisis Structural Equation Modelling (SEM) dengan metode Maximum Likelihood Estimation. Oleh karena itu maka sampel penelitian ini akan diambil dari pelanggan Speedy di Palangka Raya dengan jumlah sebanyak 110 sampel. Metode pengambilan sampel menggunakan Purposive Sampling yaitu dengan memilih sampel purposive atau sampel bertujuan secara subjektif, dimana informasi yang dibutuhkan dapat diperoleh dari satu kelompok sasaran dengan kriteria tertentu. (Ferdinand 2006). Kriteria adalah pelanggan rumah tangga yang telah menggunakan Speedy minimal 6 bulan terakhir di Palangka Raya.

Pengukuran Variabel dengan menggunakan pertanyaan-pertanyaan dalam daftar pertanyaan yang dibuat menggunakan Agree-Disagree Scale yang merupakan salah satu bentuk lain dari Bipolar Adjective dalam pengukuran data interval dengan memberikan hanya dua kategori ekstrim, dengan mengembangkan pernyataan yang menghasil-kan jawaban sangat tidak setuju - sangat setuju dalam rentang nilai misalnya 1 sampai dengan 10 di atas angka 1 menunjukan kondisi ekstrim sangat tidak setuju. Sedangkan angka 10 menunjukan kondisi ekstrim sangat setuju. (Ferdinand, 2006). Uji validitas dilakukan convergent validity dari model pengukuran dengan refleksif indikator dinilai berdasarkan korelasi antra item score/ component score dengan construct score yang dihitung dengan PLS. Ukuran refleksif individual dikatakan tinggi jika korelasi lebih dari 0,70 dengan konstruk yang ingin diukur. Namun demikian untuk penelitian tahap awal dari pengembangan skala pengukuran nilai loading factor 0,5 sampai 0,6 dianggap cukup (Ghozali, 2011). Sekaran (2006) menyatakan bahwa semakin dekat koefisien alpha yang dihasilkan pada nilai 1 berarti butir-butir pernyataan dalam koefesien semakin realibel. Besarnya nilai alpha yang dihasilkan dibandingkan dengan indeks: $>0,800$; tinggi; 0,600-0,799: sedang; <0,600: rendah. Instrumen dapat dikatakan handal jika memiliki $\mathrm{r}_{11}>0,6$. Dalam penelitian ini menggunakan data primer dari penyebaran kuesioner dengan pertanyaan-pertanyaan yang diajukan kepada responden. Responden penelitian ini adalah pelanggan Speedy di Palangka Raya. Penelitian ini menggunakan Structural Equation Modeling dengan Partial Least Square (PLS), model pengukurannya adalah menggunakan model pengukuran atau outer model dan inner 
model, dengan software Smartpls 3.0.

\section{Hasil Dan Pembahasan}

Objek dari penelitian ini adalah Speedy (produk pelayanan internet PT.TELKOM Tbk). Dimana Speedy merupakan value added dari telepon fixed wireline. Speedy merupakan pelayanan broadband akses internet melalui kabel telepon jaringan metal maupun beberapa jaringan fiber optic yang sudah banyak digunakan pelanggan telepon dengan menggunakan teknologi ADSL (Asynchronous Digital Subscriber Line) yang dapat menyalurkan data dan suara secara simultan melalui satu saluran telepon biasa (telepon rumah) dengan kecepatan yang dijaminkan sesuai dengan paket pelayanan yang diluncurkan dari modem sampai BRAS (Broadband RemoteAccess Server). (Paramitha, 2010)

Karakteristik responden adalah sebagai berikut:

a. Karakteristik responden berdasarkan jenis kelamin, yaitu responden wanita sebanyak 57 orang atau 51,82\%, sedangkan responden pria sebanyak 53 orang atau 48,18\%. Jumlah pengguna Speedy baik pria dan wanita relatif berimbang, hal ini dikarenakan Speddy tidak secara khusus memfokuskan segmentasi pasar berdasarkan jenis kelamin tertentu.

b. Karakteristik responden berdasarkan pekerjaan, yaitu responden PNS sebanyak 62 orang $(56,36 \%)$, swasta 39 orang $(35,45 \%)$, mahasiswa 7 orang $(6,36 \%)$ dan IRT 2 orang $(1,82 \%)$. Pelanggan Speedy kebanyakan dari kalangan PNS. Hal ini mengindikasikan bahwa internet merupakan sarana penunjang untuk mempermudah pekerjaan dan sarana hiburan bagi pelanggan PNS dan Swasta.

c. Karakteristik responden berdasarkan pendidikan, yaitu responden yang berpendidikan S1 sebanyak 64 orang $(58,18 \%)$, SMA sebanyak 32 orang $(29,09 \%)$, D3 sebanyak 9 orang $(8,18 \%)$ dan S2 sebanyak 5 orang $(4,55 \%)$. Hal ini mengindikasikan bahwa internet sangat dibutuhkan dan bermanfaat bagi pelanggan yang berpendidikan minimal SMA sampai dengan S2, dalam rangka mencari informasi, edukasi, dan hiburan bagi pelanggan.

d. Karakteristik responden berdasarkan penghasilan, yaitu responden yang berpenghasilan perbulan sebesar Rp 5.000.000 - Rp 7.999.000 sebanyak 39 orang (35,45\%), kemudian Rp 2.000.000 - Rp 4.999.000 sebanyak 29 orang (26,36\%), Rp 8.000.000 - Rp 10.999.000 sebanyak 22 orang (20\%), Rp11.000.000- Rp 13.999.000 sebanyak 11 orang (10\%), di atas Rp 14.000.000 sebanyak 7 orang $(6,36 \%)$ dan kurang dari Rp 2.000.000 2 orang (1,82\%). Pelanggan Speedy kebanyakan berasal dari kalangan berpenghasilan kategori kelas menengah, mengindikasikan bahwa harga Speedy terjangkau bagi kalangan berpenghasilan Rp.2.000.000 ke atas.

e. Karakteristik responden berdasarkan kelompok umur, yaitu responden yang berusia 30 - 39 tahun sebanyak 64 orang $(58,18 \%)$, responden yang berusia $20-29$ tahun sebanyak 30 orang $(27,27 \%)$ dan responden yang berusia 40-46 tahun sebanyak 16 orang $(14,55 \%)$. Hal ini mengindikasikan bahwa semua kalangan dari berbagai macam kelompok umur sudah mengakses internet terutama kelompok 30-39 tahun yang relatif terbiasa dengan teknologi internet.

Pengevaluasi Pengukuran (Measurement) Model dilakukan dengan menguji outer Modelnya. Suatu indikator dinyatakan valid jika mempunyai loading factor di atas 0,5 
terhadap konstruk yang dituju. Karena ada indikator dengan nilai di bawah 0,5 yaitu CL3 $(-0,186)$ sehingga indikator tersebut harus dibuang dan dilakukan analisis ulang.

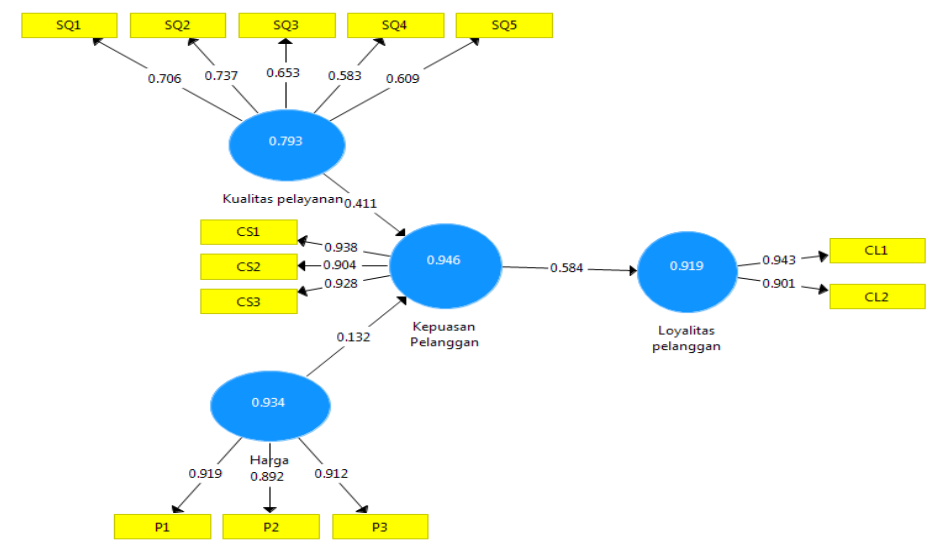

Gambar 4. Loading Factor kedua dari masing-masing Indikator

Sumber: Hasil output data primer diolah dengan Smartpls (2019)

Semua indikator memiliki loading factor di atas 0,5 terhadap konstruk yang dituju. Sehingga disimpulkan bahwa semua indikator dinyatakan valid.

Tabel 1.

Nilai Composite Reliability

\begin{tabular}{|l|c|c|}
\hline & Composite Reliability & Keterangan \\
\hline Harga & 0.934 & Reliabel \\
\hline Kualitas Pelayanan & 0.793 & Reliabel \\
\hline Kepuasan Pelanggan & 0.946 & Reliabel \\
\hline Loyalitas Pelanggan & 0.919 & Reliabel \\
\hline
\end{tabular}

Sumber: Hasil output data primer diolah dengan Smartpls (2019)

Hasil pengujian composite reliability menunjukkan nilai yang memuaskan, yaitu semua variabel laten telah reliabel karena seluruh nilai variabel laten memiliki nilai composite reliability $\geq 0,7$. Hal ini berarti bahwa, kuesioner yang digunakan sebagai instrumen penelitian telah andal atau konsisten.

Setelah model yang diestimasi memenuhi kriteria Outer Model, berikutnya dilakukan pengujian model struktural (Inner Model) untuk mengetahui Goodness of Fit Model.

Tabel 2.

Nilai R- square pada konstruk

\begin{tabular}{|l|c|} 
& $R$ Square \\
\hline Harga & - \\
\hline Kualitas Pelayanan & - \\
\hline Kepuasan Pelanggan & 0.228 \\
\hline Loyalitas Pelanggan & 0.341 \\
\hline
\end{tabular}

Sumber: Hasil output data primer diolah dengan Smartpls (2019)

Nilai $R$-square sebesar 0,228 untuk konstruk Kepuasan Pelanggan yang berarti bahwa Kualitas pelayanan dan Harga mampu menjelaskan Kepuasan Pelanggan sebesar $22,8 \%$. Nilai $R$-square konstruk Loyalitas pelanggan sebesar 0,341, artinya Kualitas pelayanan, Harga dan Kepuasan Pelanggan mampu menjelaskan Loyalitas pelanggan 
sebesar 34,1\%. Pengujian Goodness of Fit Model struktural pada inner model menggunakan nilai predictive-relevance $\left(\mathrm{Q}^{2}\right)$. Predictive-relevance diperoleh dengan rumus: $\mathrm{Q}^{2}=1-\left(1-\mathrm{R}_{1}{ }^{2}\right)\left(1-\mathrm{R}_{\mathrm{p}}{ }^{2}\right)$. Nilai predictive-relevance $\left(\mathrm{Q}^{2}\right)=1-(1-0,228)(1-$ $0,341)=0,50$. Dengan demikian model dikatakan cukup baik dan relevan, yaitu mampu menjelaskan fenomena loyalitas pelanggan sebesar 50\%, sedangkan 50\% dijelaskan oleh variabel lain di luar model.

Tabel 3

Hasil Pengujian Hipotesis

\begin{tabular}{ccccc}
\hline Hipotesis & $\begin{array}{c}\text { Original sample } \\
\text { estimate }\end{array}$ & $\begin{array}{c}\text { T- } \\
\text { Statistic }\end{array}$ & $\begin{array}{c}\text { P- } \\
\text { Values }\end{array}$ & Hipotesis \\
\hline $\begin{array}{c}\text { Kualitas Pelayanan -> } \\
\text { Kepuasan Pelanggan }\end{array}$ & $\mathbf{0 , 4 4 1}$ & $\mathbf{4 , 4 3 8}$ & $\mathbf{0 , 0 0 0}$ & diterima \\
\hline Harga -> Kepuasan Pelanggan & $\mathbf{0 , 1 3 3}$ & $\mathbf{1 , 0 4 7}$ & $\mathbf{0 , 2 9 6}$ & ditolak \\
\hline $\begin{array}{c}\text { Kepuasan Pelanggan -> } \\
\text { Loyalitas Pelanggan }\end{array}$ & $\mathbf{0 , 5 8 4}$ & $\mathbf{3 , 0 0 0}$ & $\mathbf{0 , 0 0 3}$ & diterima \\
\hline $\begin{array}{c}\text { Kualitas Pelayanan -> } \\
\text { Kepuasan Pelanggan -> } \\
\text { Loyalitas Pelanggan }\end{array}$ & $\mathbf{0 , 4 3 7}$ & $\mathbf{4 , 2 1 4}$ & $\mathbf{0 , 0 0 0}$ & diterima \\
\hline $\begin{array}{c}\text { Harga -> Kepuasan Pelanggan - } \\
\text { > Loyalitas Pelanggan }\end{array}$ & $\mathbf{0 , 4 0 3}$ & $\mathbf{3 , 4 0 8}$ & $\mathbf{0 , 0 0 0}$ & diterima \\
\hline \begin{tabular}{c} 
Sumberima \\
\hline Hasil Hulput data prima
\end{tabular} & & & \\
\hline
\end{tabular}

Sumber: Hasil output data primer diolah dengan Smartpls (2019)

Hasil pengujian hipotesis menunjukkan bahwa:

H1: Kualitas pelayanan berpengaruh positif dan signifikan terhadap kepuasan pelanggan adalah diterima.

$\mathrm{H} 2$ : Harga berpengaruh positif dan signifikan terhadap terhadap kepuasan pelanggan adalah ditolak.

H3: Kepuasan pelanggan berpengaruh positif dan signifikan terhadap terhadap loyalitas pelanggan adalah diterima.

H4: Kualitas pelayanan berpengaruh positif dan signifikan terhadap loyalitas pelanggan yang dimediasi oleh kepuasan pelanggan adalah diterima.

H5: Harga berpengaruh positif dan signifikan terhadap loyalitas pelanggan yang dimediasi oleh kepuasan pelanggan adalah diterima.

Hasil riset ini dapat memperkuat konsep-konsep teoritis dan memberikan dukungan empiris terhadap temuan penelitian terdahulu.

1. Pernyataan bahwa kualitas pelayanan berpengaruh terhadap kepuasan pelanggan dalam penelitian ini adalah terbukti. Hal tersebut memperkuat/ mendukung temuan sebelumnya yaitu kepuasan pelanggan dipengaruhi oleh kualitas pelayanan (service quality), seperti yang dinyatakan oleh Bei dan Chiao (2001); Akbar dan Parvez (2009); Omar et al. (2009); Krismanto (2009). Kualitas pelayanan pelanggan memainkan peran penting dalam membangun kepuasan pelanggan. Kepuasan berhubungan langsung dengan kemampuan penyedia pelayanan untuk memberikan pelayanan kepada pelanggan dengan cepat dan efisien yang akan meningkatkan kepuasan dan retensi. Hasil dalam penelitian ini menunjukkan bahwa apa yang diterima pelanggan dari kualitas pelayanan yang diberikan Speedy sudah memenuhi atau melebihi kebutuhan, keinginan dan harapan pelanggan Speedy. 
2. Pernyataan bahwa harga berpengaruh terhadap kepuasan pelanggan dalam penelitian ini adalah tidak terbukti. Hal tersebut memperkuat/mendukung temuan sebelumnya oleh Angin (2009), Aidasanti (2010) dan Cheng et al (2011) yang menyatakan bahwa harga tidak mempengaruhi kepuasan pelanggan. Menurut Parasuraman dkk (1988) harga adalah sesuatu yang harus dikorbankan untuk mendapatkan beberapa jenis produk dan jasa, dimana semakin rendah harga yang dirasakan maka semakin rendah pula pengorbanan yang dirasakan dan pelanggan lebih puas akan harga yang dirasakan dari keseluruhan transaksi yang diciptakan. Jadi harga yang lebih rendah tidak menjamin kepuasan yang lebih tinggi. Harga yang ditetapkan Speedy dalam penelitian ini bukan merupakan hal yang fundamental dan hal yang sangat penting dalam membangun kepuasan pelanggan. Faktor-faktor yang mempengaruhi kepuasan pelanggan adalah mutu produk dan pelayanannya, kegiatan penjualan, pelayanan setelah penjualan dan nilai-nilai perusahaan. (Angin, 2009)

3. Pernyataan bahwa kepuasan pelanggan berpengaruh terhadap loyalitas pelanggan dalam penelitian ini adalah terbukti positif dan signifikan. Artinya kepuasan pelanggan merupakan faktor penting yang berpengaruh secara langsung terhadap loyalitas pelanggan, dimana semakin tinggi kepuasan pelanggan yang diberikan perusahaan maka semakin tinggi pula loyalitas pelanggan tersebut. Hal tersebut memperkuat/ mendukung temuan sebelumnya oleh Wijayanti (2008); Akbar dan Parvez (2009); Anuwichanont dan Mechinda (2009); Krismanto (2009); Syafiq (2010); Chen dkk (2010); Eid (2011) yang menyatakan bahwa kepuasan pelanggan berpengaruh terhadap loyalitas pelanggan.

4. Pernyataan bahwa kualitas pelayanan berpengaruh positif dan signifikan terhadap loyalitas pelanggan yang dimediasi oleh kepuasan pelanggan dalam penelitian ini adalah terbukti. Hal tersebut memperkuat/mendukung temuan yang dinyatakan oleh Bei dan Chiao (2001), Akbar dan Parvez (2009); dan Sukmawati dan Massie (2015).

5. Pernyataan bahwa harga berpengaruh positif dan signifikan terhadap loyalitas pelanggan yang dimediasi oleh kepuasan pelanggan dalam penelitian ini adalah terbukti. Hal tersebut memperkuat/ mendukung temuan yang dinyatakan oleh Bei dan Chiao (2001) dan Hidayat, D.R. dan Firdaus, M.R. (2014)

Berdasarkan outer loading dari variabel kualitas pelayanan, yang dominan adalah item pernyataan yaitu Speedy memberikan pelayanan sesuai janji. Semakin Speedy memberikan pelayanan internet yang menarik, semakin Speedy memberikan pelayanan tepat waktu, semakin Petugas Speedy dapat meyakinkan kebaikan speedy kepada pelanggan, semakin Petugas Speedy mengutamakan pelayanan ke pelanggan, dan semakin Petugas Speedy mampu menarik perhatian pelanggan maka semakin meningkat kepuasan pelanggan. Kualitas pelayanan terbaik yang sudah diberikan Speedy Palangka Raya adalah Akses internet cepat, pelayanan handal, peralatan canggih, pengetahuan petugas tentang produk, perhatian dan keramahan petugas jaringan kuat, dan respon cepat. Sedangkan kualitas pelayanan yang perlu diperbaiki adalah modem ganguan jaringan, akses/koneksi/kecepatan internet tidak stabil, pelayanan petugas ke pelanggan. Berdasarkan outer loading dari variabel harga, yang dominan item pernyataan yaitu Harga paket internet bulanan Speedy yang dibayar tidak berbeda jauh dari perkiraan pelanggan. Semakin harga paket internet bulanan Speedy yang dibayar berbeda jauh dari perkiraan pelanggan maka semakin Pelanggan berniat menggunakan terus menerus Speedy. Kondisi ini bisa saja terjadi ketika Speedy menjadi 
satu-satunya pilihan operator yang melayani broadband wireline di Palangka Raya, atau pelanggan memang orang yang sangat loyal dengan Speedy. Pelanggan memandang produk Speedy sebagai produk yang berkualitas dengan harga yang murah (relatif terjangkau). Usaha yang dapat dilakukan Speedy terkait dengan kebijakan harga diantaranya sebagai berikut : menetapkan bahwa harga paket internet bulanan Speedy yang dibayar pelanggan fixed perbulan sesuai dengan pilihan paket masing-masing pelanggan. Meyakinkan pelanggan bahwa harga paket internet Speedy yang dibayar sepadan dengan pelayanan yang didapatkan pelanggan dan merupakan harga yang relatif murah dan wajar jika dibandingkan dengan operator lain. Memberikan strategi diskon kepada pelanggan. Strategi harga yang diambil Speedy tetap menjaga dan meningkatkan kualitas pelayanan yang sudah ada saat ini. Berdasarkan factor loading variabel kepuasan pelanggan yang dominan dengan item pernyataan yaitu Pelanggan merasa senang selama menggunakan Speedy yaitu Secara keseluruhan pelanggan puas dengan kinerja Speedy. Dan factor loading untuk variabel loyalitas, dominan item pernyataan yaitu Pelanggan berniat menggunakan terus menerus Speedy. Artinya Semakin meningkat secara keseluruhan kepuasan pelanggan dengan kinerja Speedy maka semakin meningkatkan kepercayaan pelanggan dengan pelayanan Speedy. Dan Semakin meningkat secara keseluruhan kepuasan pelanggan dengan kinerja Speedy maka semakin pelanggan berniat menggunakan terus menerus Speedy. Semakin meningkat kualitas pelayanan dan harga, maka akan semakin meningkatkan pula tingkat loyalitas pelanggan kepada Speedy, melalui kepuasan pelanggan sebagai mediasinya. Karena merasa akses internet Speedy telah sesuai dengan harapan yang inginkan sehingga secara keseluruhan pelanggan puas dengan kinerja Speedy.

\section{SIMPULAN}

Kualitas pelayanan berpengaruh positif dan signifikan terhadap Kepuasan pelanggan adalah diterima. Harga berpengaruh terhadap kepuasan pelanggan dalam penelitian ini adalah tidak diterima. Kepuasan pelanggan berpengaruh positif dan signifikan terhadap loyalitas pelanggan adalah diterima. Kualitas pelayanan berpengaruh positif dan signifikan terhadap loyalitas pelanggan yang dimediasi oleh kepuasan pelanggan adalah diterima. Harga berpengaruh positif dan signifikan terhadap loyalitas pelanggan yang dimediasi oleh kepuasan pelanggan adalah diterima.

Speedy dapat merespon dan melakukan recovery dengan cepat segala jenis pengaduan yang sering dikeluhkan pelanggan yaitu gangguan jaringan, kecepatan akses yang tidak stabil, koneksi yang sering putus, serta penanganan gangguan yang lambat. Ketidakpuasan pelanggan akan berdampak pada cabutan (churn) atau berhenti berlangganan yang terus meningkat. Hal ini juga akan berdampak pada pendapatan jangka panjang perusahaan. Speedy dapat mempertahankan dan meningkatkan pelayanan terbaiknya berdasarkan informasi dari pelanggan Speedy yaitu Speedy memberikan kualitas pelayanan akses internet cepat dan stabil, harganya standar dan relatif terjangkau, mempertahankan citra perusahaan sebagai pemimpin pasar untuk akses internet wireline di Indonesia, memperhatikan kinerja Speedy yang berorientasi pada kepuasan pelanggan dan bahkan kinerjanya bisa melebihi harapan pelanggan Speedy.

Keterbatasan Penelitian penelitian ini yaitu Berdasarkan nilai prediktif model pengaruh Kualitas pelayanan, Harga, dan Kepuasan pelanggan adalah sebesar $50 \%$ 
dapat menjelaskan Loyalitas pelanggan Speedy sedangkan $50 \%$ dijelaskan oleh variabel lain di luar model, masih setengah bagian faktor yang mempengaruhi Loyalitas belum tercover dalam model ini. Untuk penelitian selanjutnya tentang loyalitas pelanggan bisa melanjutkan penelitian ini dengan mereplikasi penelitian ini dengan menambah jumlah variabel penelitian yang mempengaruhi loyalitas disamping variabel yang sudah ada, misalnya variabel commitment, complaints, switching cost, Brand Image, dll, serta menambah ukuran sampel minimal 200 sampel.

\section{REFERENSI}

Agung, Ken Hermanto 2006, “Analisis Pengaruh Kualitas Layanan, Komitmen, dan Kepercayaan Terhadap Loyalitas Konsumen (Studi Kasus Pada Nasabah Tabungan SIMPEDA Bank JATENG)" Tesis, Magister Manajemen, Universitas Diponegoro.

Aidasanti, Feni 2010, Pengaruh service quality dan price fairness terhadap customer loyalty dengan corporate image, trust dan customer satisfaction sebagai variabel pemediasi (studi kasus pada konsumen pusat perawatan kecantikan larissa di surakarta). Skripsi, UNS, Surakarta.

Akbar, Mohammad Muzahid and Md. Munir Munir, (2009) Structural Equation Modeling on the Antecedents of Customer Loyalty.

$\langle$ http://www.wbiconpro.com/508-Munir.pdf $>$

Akbar, Mohammad Muzahid and Noorjahan Parvez 2009, Impact of Service Quality, Trust, and Customer Satisfaction on Customers Loyalty', ABAC Journal Vol. 29, No. 1 January-April 2009, pp.24-38.

Andreassen, Tor Wallin, and Bodil Lindestad 1997, "Customer Loyalty and Complex Services : The Impact of Corporate Image on Quality, Customer Satisfaction and Loyalty For Costumers With Varying Degrees of Service Expertise", The International Journal of Service Industry Management, vol 8, No 4.

Angin, Jasanta Perangin. 2009, "Studi Peningkatan Loyalitas Pelanggan Ritel (Studi Kasus Toko Amelina)" Tesis, Magister Manajemen, Universitas Diponegoro.

Anuwichanont, Jirawat, and Panisa Mechinda 2009, "The Impact Of Perceived Value On Spa Loyalty And Its Moderating Effect Of Destination Equity”, Journal of Business dan Economics Research Volume 7, Number 12.

Bei, Lien-Ti Chiao Yu-Ching 2001, "An Integrated Model For The Effect Of Perceived Product, Perceived Service Quality And Perceived Price Fairness On Consumers," Journal of Consumer Satisfaction, Dissatisfaction And Complaining Behavior, Volume 14, 2001 pp 125-140.

Boohene, Rosemond and Gloria K.Q. Agyapong 2011, "Analysis of the Antecedents of Customer Loyalty of Telecommunication Industry in Ghana: The Case of Vodafone (Ghana)", International Business Research Vol. 4, No. 1.

Chang, Nai-Jen and Cher-Min Fong 2010, "Green Product Quality, Green Corporate Image, Green Customer Satisfaction, and Green Customer Loyalty", African Journal of Business Management Vol. 4(13), pp. 2836-2844.

Chen, Huei-Huang, Shih-Chih Chen dan Chih-Chin Yang 2010, "The Impact of Service Quality and Relationship Quality on Customer Loyalty in Etourism". <http://bai-onference.org/files/BAI2010\%20Proceeding/Papers/2. 
Marketing 2304.pdf>

Cheng, T. C. E., L. C. F. Lai, A. C. L. Yeung 2009, "The Driving Forces of Customer Loyalty: A Study of Internet Service Providers in Hong Kong". $<$ http://www.igiglobal.com/gateway/edatabasetools/databasesearch.aspx>

Cheng, Ching Chan, Shao-I Chiu, Hsiu-Yuan Hu, dan Ya-Yuan Chang (2011), “A study on exploring the relationship between customer satisfaction and loyalty in the fast food industry: With relationship inertia as a mediator", African Journal of Business Management Vol. 5(13), pp. 5118-5126.

Djati, S Pantja; Darmawan, Didit 2004, "Pengaruh Kesan Kualitas Pelayanan, Harga, dan Kepuasan Mahasiswa Terhadap Minat Mereferensikan", Jurnal Widya Manajemen dan Akuntansi, Vol 4 No 2.

Eid, Mustafa I 2011, "Determinants of E-Commerce Customer Satisfaction, Trust, and Loyalty in Saudi Arabia” Journal of Electronic Commerce Research, VOL 12, NO 1, 2011.

Ferdinand, A., 2006, "METODE PENELITIAN MANAJEMEN : Pedoman Penelitian Untuk Penulisan Skripsi, Tesis dan Disertasi Ilmu Manajemen", edisi ke-2 BP Undip Semarang.

Ghozali, Imam, 2011, "MODEL PERSAMAAN STRUKTURAL : Konsep dan Aplikasi Dengan Program AMOS 19.0 edisi 4 BP Undip Semarang.

Hellier, Philip K; Geursen, Gus M; Carr, Rodney A; Rickard, John A 2003, "Customer Repurchase Intention A General Structural Equation Model," European Journal of Marketing, Vol.37, No 11/12.

Hidayat, D.R. dan Firdaus, M.R. 2014. “Analisis Pengaruh Kualitas Pelayanan, Harga, Kepercayaan, Citra Perusahaan dan Kepuasan Pelanggan terhadap Loyalitas Pelanggan (Studi pada Pelanggan Telkom Speedy di Palangka Raya)". Jurnal Wawasan Manajemen. Vol. 2, No. 3. p. 237-249.

Ishaq, Muhammad Ishtiaq 2012, "Perceived Value, Service Quality, Corporate Image, and Customer Loyalty : Empirical Assessment From Pakistan", Serbian Journal of Management 7 (1) $25-36$.

Kotler, P.T dan Keller K.L, 2011, Marketing Management14th, Prentice Hall, New Jersey

Krismanto, Adi 2009, “Analisis Faktor-Faktor yang Mempengaruhi Loyalitas Nasabah" Tesis, Magister Manajemen, Universitas Diponegoro.

Laporan Tahunan PT Telekomunikasi Indonesia Tbk 2015.

Omar, Nor Asiah, Muhammad Azrin Nazri, Nor Khalidah Abu, Zoharah Omar 2009, "Parents' Perceived Service Quality, Satisfaction and Trust of a Childcare Centre : Implication on Loyalty" International Review of Business Research Papers, Vol. 5 No. 5 September 2009, pp. 299-314

Paramitha, Rany Aulia 2010, “Analisis Faktor Kepercayaan dan implikasinya terhadap loyalitas pelanggan pada produk Speed” (Pelanggan Prime Kandatel Semarang), Tesis, Magister Manajemen, Universitas Diponegoro.

Parasuraman A, Zeithaml, Valerie A, Berry, Leonard L 1988, "SERVQUAL- A Multiple-Item Scale for Measuring Consumer Perceptions of Service Quality", Journal of Retailing, Vol 64 (Spring), pp. 12-40

Parvez, Masud 2005,"A relational study on service quality, switching cost, trust, 
customer satisfaction and customer loyalty in the context of GrameenPhone" Internship report-Independent University,Bangladesh

Sekaran, Uma 2000, Research Methods For Business : A Skill-Building Aproach, $3^{\text {th }}$ Edition, New York : John Wiley dan Sons

Singh, Harkiranpal 2006, "The Importance of Customer Satisfaction in Relation to

Customer Loyalty and Retention," UTCI Working Paper, WP-06-06

Sukmawati,I dan Massie, J.D.D.2015. Pengaruh Kualitas Pelayanan Dimediasi

Kepuasan Pelanggan Dan Kepercayaan Pelanggan Terhadap Loyalitas

Pelanggan Pada PT Air Manado. Jurnal EMBA Vol.3 No. 3, Hal.729-742.

Syafiq, Ali 2010, “Analisis Pengaruh Kualitas Pelayanan, Kepercayaan, dan Kepuasan

Terhadap Loyalitas Pelanggan Telkomspeedy Dengan Metode Structural Equation Modeling" Tesis, Magister Manajemen Teknologi, Institut Teknologi Sepuluh Nopember.

Wijayanti, Ari 2008, “Strategi Meningkatkan Loyalitas Melalui Kepuasan Pelanggan (Studi Kasus: Produk Kartu Seluler PraBayar Mentari-Indosat Wilayah Semarang)", Tesis, Magister Manajemen, Universitas Diponegoro.

Zhang, Xuan dan Yuan Feng 2009, “The Impact of Customer Relationship Marketing Tactics On Customer Loyalty - Within Swedish Mobile Telecommunication Industry" Thesis, Master Program in International Marketing, Halmstad University. 